\title{
Multi-physics Design Optimisation of PM- assisted Synchronous Reluctance Motor for Traction Application
}

\author{
Mahir Al-ani \\ Department of Electrical and \\ Electronic Engineering \\ University of Nottingham \\ Nottingham, UK \\ mahir.al-ani@nottingham.ac.uk \\ Ramkumar Ramanathan \\ Department of Electrical and \\ Electronic Engineering \\ University of Nottingham \\ Nottingham, UK \\ ramanathan.ramkumar@, \\ nottingham.ac.uk \\ Antonino La Rocca \\ Department of Electrical and \\ Electronic Engineering \\ University of Nottingham \\ Nottingham, UK \\ A.larocca@ nottingham.ac.uk \\ Krzysztof Paciura \\ Cummins Corporate R\&T \\ Cummins Ltd \\ Peterborough, UK \\ krzysztof.paciura@cummins.com
}

\author{
Adam Walker \\ Department of Electrical and \\ Electronic Engineering \\ University of Nottingham \\ Nottingham, UK \\ adam.walker5@nottingham.ac.uk
}

\author{
Tianjie Zou \\ Department of Electrical and \\ Electronic Engineering \\ University of Nottingham \\ Nottingham, UK \\ tianjie.zou@nottingham.ac.uk
}

\author{
David Gerada \\ Department of Electrical and \\ Electronic Engineering \\ University of Nottingham \\ Nottingham, UK \\ david.gerada@nottingham.ac.uk
}

\author{
Alastair McQueen \\ Cummins Corporate R\&T \\ Cummins Ltd \\ Peterborough, UK \\ alastair.mcqueens@cummins.com
}

\author{
Gaurang Vakil \\ Department of Electrical and \\ Electronic Engineering \\ University of Nottingham \\ Nottingham, UK \\ gaurang.vakil@ nottingham.ac.uk
}

Salvatore La Rocca

Department of Electrical and

Electronic Engineering

University of Nottingham

Nottingham, UK

salvatore.larocca@nottingham.ac.uk

\author{
Chris Gerada \\ Department of Electrical and \\ Electronic Engineering \\ University of Nottingham \\ Nottingham, UK \\ chris.gerada@nottingham.ac.uk
}

\begin{abstract}
Recently, the synchronous reluctance machine limits have been pushed toward meeting the requirements of traction applications. A skilled electromagnetic architecture of a synchronous reluctance machine with the help of permanent magnets can push the limits of power density and speed range to that of traction applications, however, the mechanical integrity of the rotor can still be in question. A traction application means large rotor diameter and high rotational speed, two criteria that makes a challenging design, in particular, mechanically. In this paper, the multi-physics design steps of a permanent magnets assisted synchronous reluctance motor for automotive application, have been presented. Firstly, the electromagnetic design following the size and thermal aspects and constrains has been conducted. Secondly, methods to reduce the mechanical stress has been explored and a bridged mechanical design has been adapted. Finally, thermal analysis of the machine has been conducted to ensure the thermal limits have been satisfied.
\end{abstract}

Keywords- Synchronous reluctance, PM assisted, mechanical stress, mechanical design, IPM, traction application, automotive application

\section{INTRODUCTION}

Attempts to introduce the synchronous reluctance (SynRel) machine to traction application has been reported lately in [1-4]. Obstacles of limited torque-speed range and low power factor have been addressed by including permanent magnets (PMs), i.e. PM assisted synchronous reluctance (PMSynRel) machine. Compared to the conventional interior permanent magnet (IPM) machine, the PM-SynRel offers higher reluctance torque and therefore higher torque per magnet volume [5]. However, similar to the IPM machine the presence of the PMs adds complicity to the structural design of the rotor when considering the high peripheral speed.

This paper presents a multi-physics design steps of an electric motor for a traction application. The electromagnetic 
design started by a detailed parametric optimization. The optimized electromagnetic design (D1) is then mechanically investigated to identify the mechanical challenges and limitations. The mechanical investigation started with studying the debonding of the adhesive that is used to hold the PMs to understand the effect of the adhesive on the structural integrity of the rotor. Following, different methods to reduce the maximum stress to the acceptable material limit were explored, including applying retaining sleeve, and adding internal bridges to hold the PMs. The final design consisted of bridged rotor core to enclose the magnets. The final modified design (D2) is then electromagnetically analysed to evaluate the performance degradation. Finally, thermal analysis of the final electromagnetic and mechanical design (D2) has been conducted to ensure the thermal safety, i.e. satisficing the thermal limits.

\section{Design SpecificATIONS AND APPLICATION REQUIREMENTS}

The electric motor is designed for a traction. Such application requires a high torque density along a wide speed range. Table I lists the main design specification and required performance. Fig. 1 presents the torque-speed profile for the peak and continues operation.

Table I Main design specifications and requirements

\begin{tabular}{|l|c|}
\hline Parameter & Value \\
\hline Peak Power $(\mathrm{kW})$ & 220 \\
\hline Peak Time $(\mathrm{s})$ & 30 \\
\hline Peak Torque $(\mathrm{Nm})$ & 750 \\
\hline Ideal Continuous Power $(\mathrm{kW})$ & 150 \\
\hline Acceptable Continuous Power $(\mathrm{kW})$ & 130 \\
\hline Ideal Continuous Torque (Nm) & 511 \\
\hline Acceptable Continuous Torque (Nm) & 444 \\
\hline Base Speed (rpm) & 2800 \\
\hline Max Speed (rpm) & 15000 \\
\hline Max Winding Temp $\left({ }^{\circ} \mathrm{C}\right)$ & 180 \\
\hline DC Link Voltage Range $(\mathrm{V})$ & 620 to 760 \\
\hline DC Link Voltage Rated (V) & 660 \\
\hline Target Mass (kg) & 140 \\
\hline Target Minimum Efficiency (\%) & 95 \\
\hline Laminated steel & HXT780T \\
\hline PM grade & N38UH, Br $1.26 \mathrm{~T}$ \\
\hline
\end{tabular}

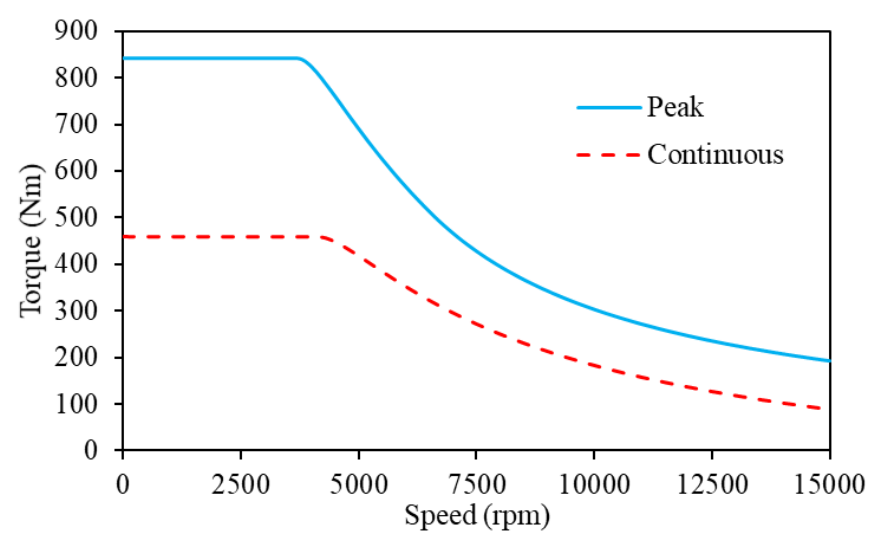

Fig. 1 Torque-speed profile of the peak and continuous operation.

\section{EleCtromagnetic Design (D1)}

The PM-SynRel topology has been globally optimized using generic algorithm for defined objective functions. Table II lists the optimization constrains, degrees of freedom and objectives. Fig. 2 presents the machine geometrical parameters included in the optimization. The final electromagnetically optimized designed machine (D1) is shown in Fig. 3.

Table II Optimized parameters

\begin{tabular}{|l|c|}
\hline Parameter & Constrains \\
\hline \multicolumn{2}{|c|}{} \\
\hline Outer diameter (mm) & 300 \\
\hline Axial length (mm) & 300 \\
\hline Airgap length (mm) & 1.8 \\
\hline \multicolumn{2}{|c|}{ Degrees of freedom } \\
\hline Split ratio & $0.4-0.7$ \\
\hline Slot height (mm) & $10-20$ \\
\hline Back-iron thickness (mm) & $10-20$ \\
\hline $1^{\text {st layer magnet fill percentage }}$ & $0-100$ \\
\hline $2^{\text {nd }}$ layer magnet fill percentage & $0-100$ \\
\hline $3^{\text {rd }}$ layer magnet fill percentage & $0-100$ \\
\hline Number of turns per coil & $7-15$ \\
\hline Number of parallel paths & 1,5, and 10 \\
\hline \multicolumn{2}{|c|}{ Objectives } \\
\hline Peak power (kW) & $\geq 250$ \\
\hline Efficiency & $\geq 94$ \\
\hline PM mass (kg) & $\geq 140$ \\
\hline Machine mass (kg) & $\leq 10$ \\
\hline Torque ripple & \\
\hline
\end{tabular}

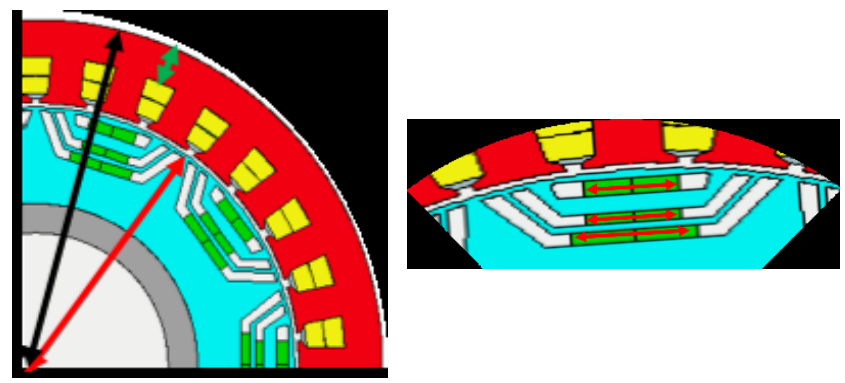

Fig. 2 Optimized design parameters.

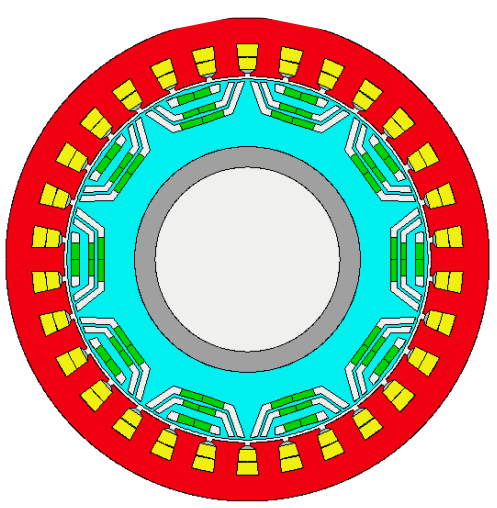

Fig. 3 Electromagnetically optimized design (D1). 


\section{Mechanical Design (D2)}

Using FEA, the rotor of D1 has been studied and redesigned to ensure mechanical safety. The boundary condition is a fixed inner surface of the rotor, whereas the load is a rotation speed of $16.5 \mathrm{krpm}$, i.e. $10 \%$ speed safety margin. Table III lists the properties of the rotor core and magnets. The maximum allowed stress in the rotor is set to $720 \mathrm{MPa}$ allowing an extra $10 \%$ stress safety margin.

Table III Comparison of SPM, IPM and SynRel-PM.

\begin{tabular}{|l|c|c|}
\hline Parameter & Steel & PM \\
\hline Mass density $\left(\mathrm{kg} / \mathrm{m}^{3}\right)$ & 7650 & 7500 \\
\hline Young's modulus $(\mathrm{MPa})$ & 200 & 160 \\
\hline Poisson's ratio & 0.3 & 0.3 \\
\hline Yield strength $(\mathrm{GPa})$ & 800 & 60 \\
\hline
\end{tabular}

\section{A. Debonding}

Initially, the adhesive strength has been evaluated to obtain if the adhesive would experience a debonding or not. Therefore, the magnet contact with the rotor core has been set to bonded contact with adhesive properties. It is worth noting that although using a stronger adhesive will maintain the bond between the magnet and core, the PM will experience a high stress that would surpass the yield limit strength of the PMs. Fig. 4 presents the stress distribution in the rotor when the contact are bonded and debonded. Fig. 5 presents the bottom magnet contact maximum equivalent (von-Mises) stress and maximum deformation at different rotor speeds, it can be seen at low speed, i.e. 5000rpm, the cohesive strength between the steel and magnet on the inner magnet surface has failed. The debonding between the magnets and the core which results in significantly high mechanical stress at the rotor outer bridges. (a) Maximum stress

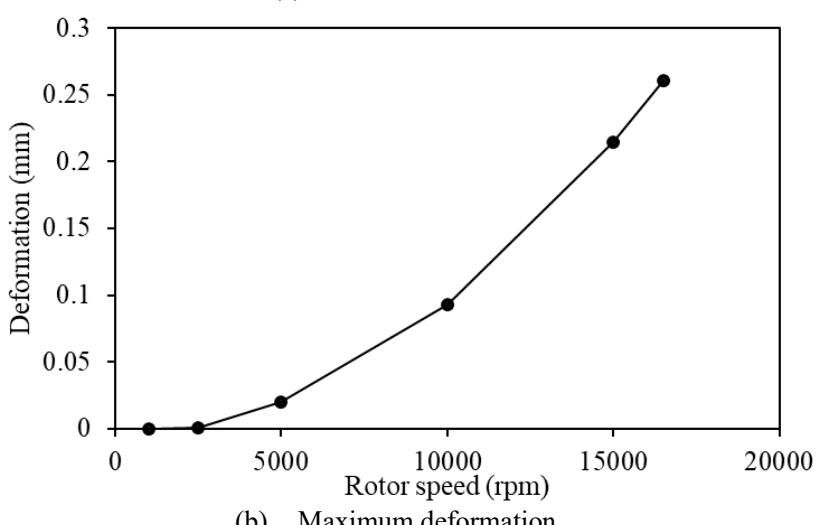

(b) Maximum deformation

Fig. 5 Adhesive contact performance at different rotor speeds

\section{B. Sleeve}

A $0.8 \mathrm{~mm}$ thick carbon fibre retaining sleeve has been applied to the rotor with an interference fit of $0.08 \mathrm{~mm}$. Fig. 6 presents the stress distribution of the rotor at speed of $16.5 \mathrm{krpm}$. Although the maximum stress has been reduced from $2915 \mathrm{MPa}$ to $2570 \mathrm{Mpa}$.

Although the sleeve has managed to reduce the maximum stress by decreasing the deformation along the magnets, the reduction is relatively small. Using thicker sleeve with higher interface fit by reducing the rotor outer frame thickness, i.e. $3 \mathrm{~mm}$ sleeve with $0.3 \mathrm{~mm}$ interference fit, has reduced the stress further, however, $1979 \mathrm{MPa}$ still significantly higher than the limit. In addition, manufacturing difficulties are expect to assemble a $0.3 \mathrm{~mm}$ interference fit sleeve. These reasons making the sleeve infeasible for this design.

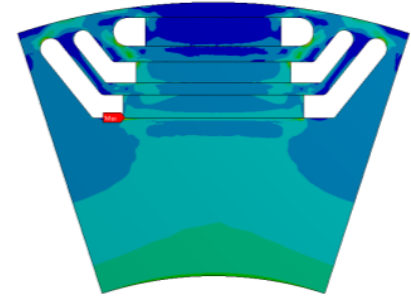

(a) Bonded

Fig. 4 Mechanical stress destitution in the rotor.

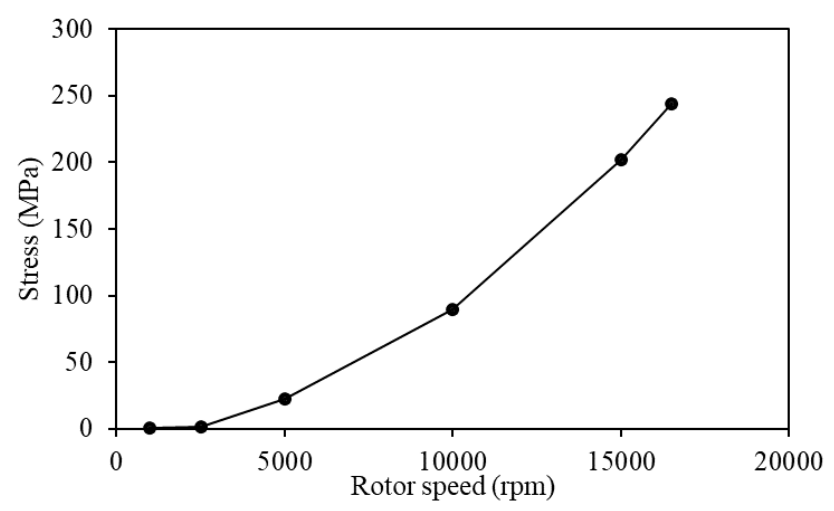

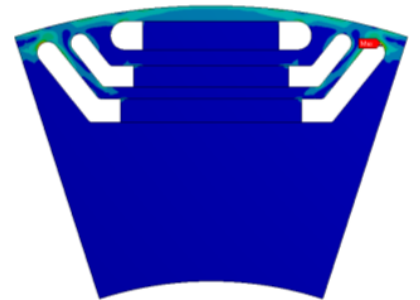

(b) Debonded

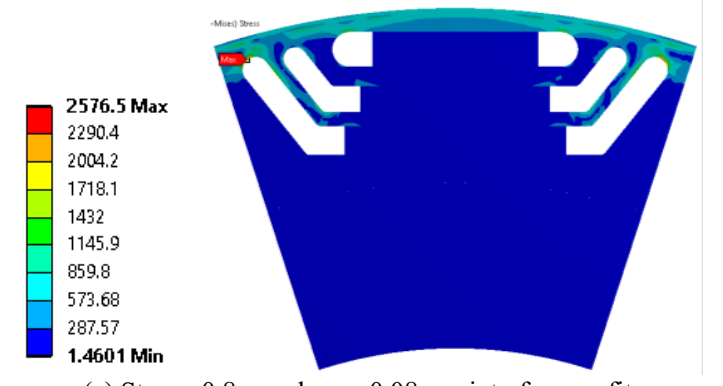

(a) Stress, $0.8 \mathrm{~mm}$ sleeve, $0.08 \mathrm{~mm}$ interference fit

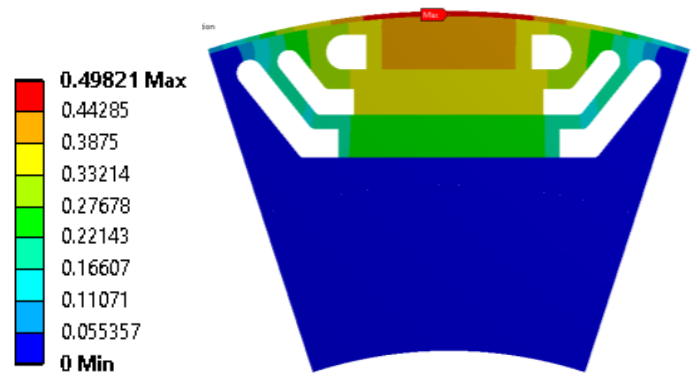

(b) Deformation, $0.8 \mathrm{~mm}$ sleeve, $0.08 \mathrm{~mm}$ interference fit 


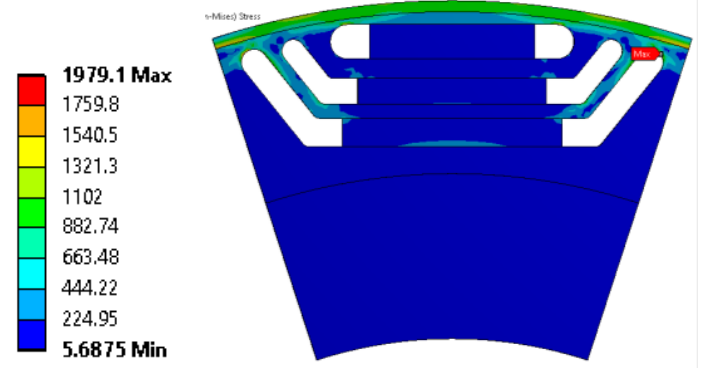

(c) Stress, $3 \mathrm{~mm}$ sleeve, $0.3 \mathrm{~mm}$ interference fit

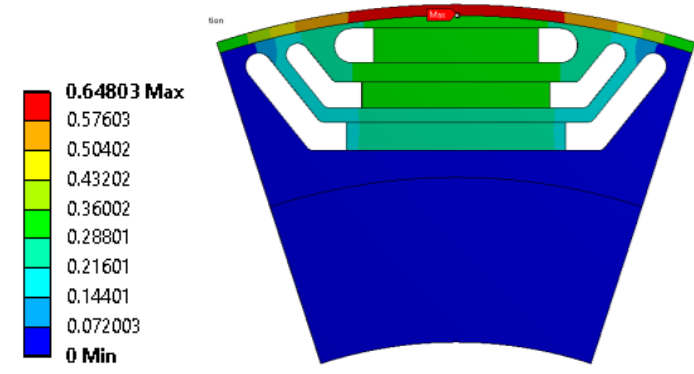

(d) Deformation, $3 \mathrm{~mm}$ sleeve, $0.3 \mathrm{~mm}$ interference fit

Fig. 6. Stress and deformation of the rotor D1 with carbon fiber sleeve.

\section{Brdiges}

By observing the stress and deformation in the rotor, Fig. 7 , it can be seen that the highest deformation occurs at the centre line of the rotor, this places a high stress on the outer frame. Therefore, retain the central line of the rotor is expected to reduce the stress.

Firstly, bridges at both sides of the magnets were added. Although the maximum stress reduced, the large deformation along the central line is still high and therefore, the stress still high as shown in Fig. 8. Bridges along the central line were added in addition to the side bridges. The magnets have been segmented into two parts separated by bridges to reduce the deformation at the middle line, side bridges are added to lock the magnets in their location and avoid any magnet slipping. Fig. 9 shows the rotor stress and deformation, since the maximum stress has been reduced to 590MPa which is lower than the limit of the safety limit of the material.

Further changes are conducted to maintain the rotor stress within the acceptable limit and minimize the bridges thicknesses to enhance the electromagnetic performance. Fig. 9 presents the four different iterations together with their stress and deformation. The iterations include shaping and reducing the bridges thicknesses. The final design (D2) is shown in Fig. 9 (fourth iteration).

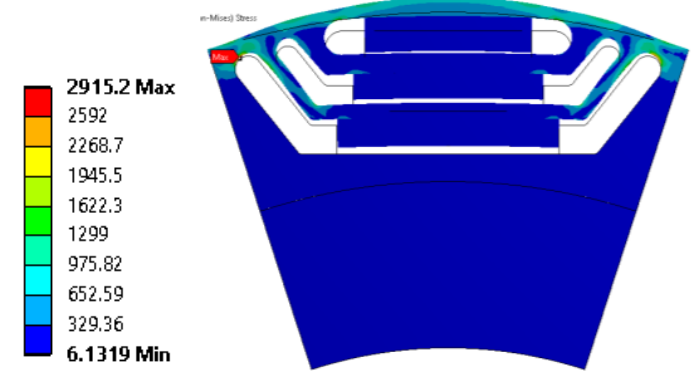

(a) Stress

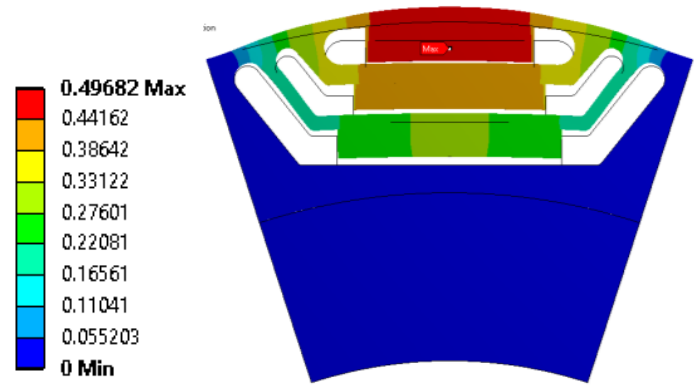

(b) Deformation

Fig. 7. Stress and deformation of the D1 design.

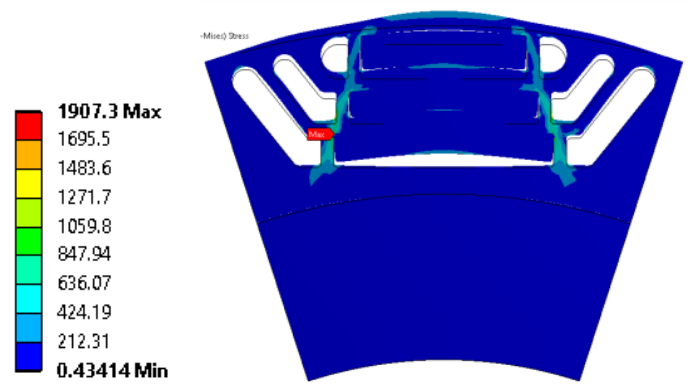

(c) Stress

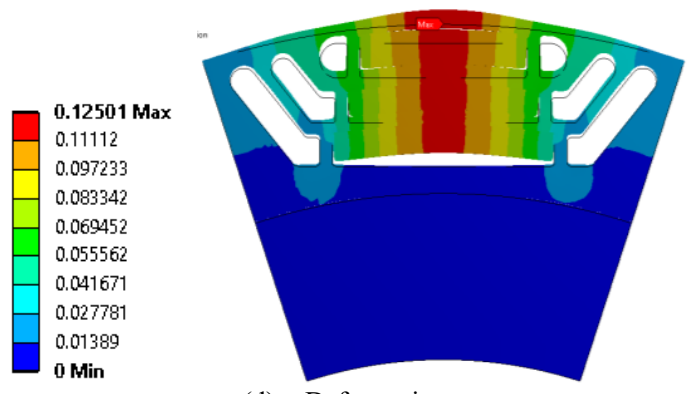

(d) Deformation

Fig. 8. Stress and deformation of the D1 design with side bridges.

\section{Investgating the Electroamgetnic Performance}

The D2 has been analysed electromagnetically, as expected, the bridges creates short-circuit paths for the PM flux. Therefore, a reduction in the performance has been observed. However, the initial electromagnetic design (D1) has been over-designed, i.e. the torque-speed characteristics are higher than that of the target shown in Fig.1. This is to take in consideration any possible performance degradation comes from mechanical designing. Therefore, the mechanically 
modified design (D2) has satisfactory torque-speed curve. As a result, not changes are required. Fig. 10 presents the torquespeed characteristics of the D1 and D2 designs.

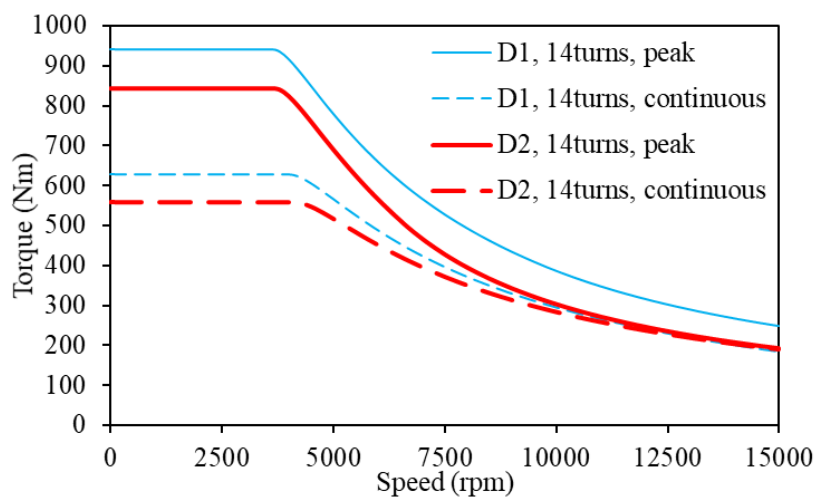

(a) Torque-speed curve

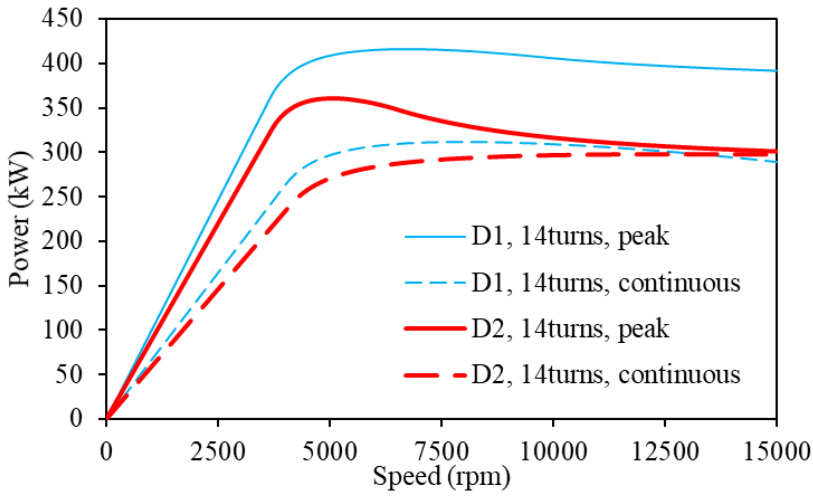

(b) Power-speed curve
Fig. 9. Torque-speed characteristics of the D1 and D2 machines.

\section{THERMAL ANALYSIS}

Using LPC, thermal analysis of the D2 has been conducted to ensure thermal safety. Cooling jacket with a $9.6 \mathrm{~L} / \mathrm{min}$ flow rate, $65^{\circ} \mathrm{C}$ inlet temperature and EGW50/50 fluid has been used. A duty cycle of 30 second peak condition, i.e. maximum losses at peak operation, has been employed. Fig. 11 presents the temperature at different parts of the machine and Table IV lists the temperature in the different machine parts. Since the thermal performance satisfy the design requirements, no changes for the design are needed.

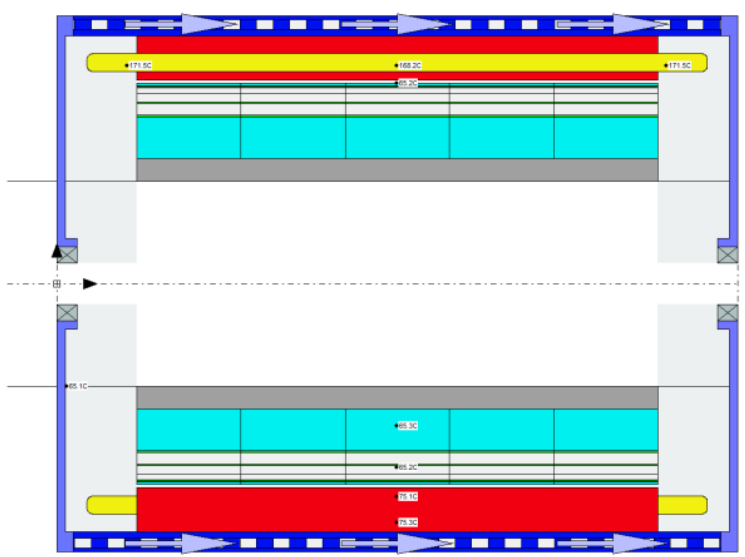

Fig. 10. Thermal layout and temperatures in different parts of D3 at 30 second peak condition.

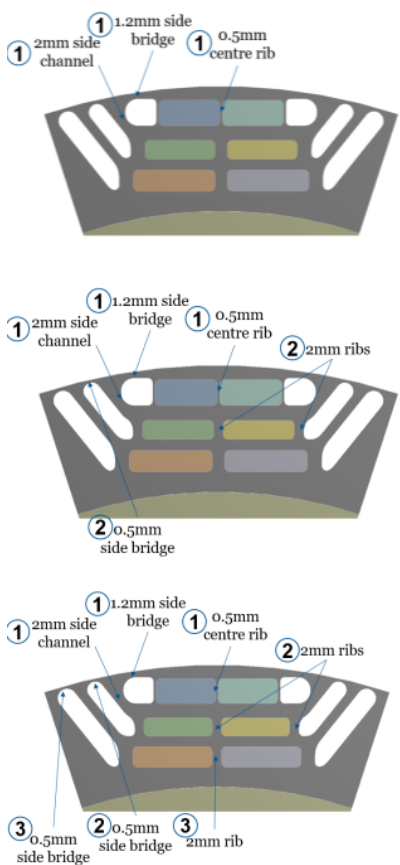

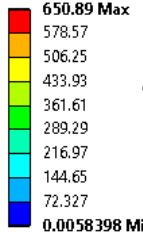

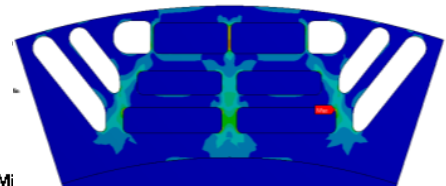

First iteration
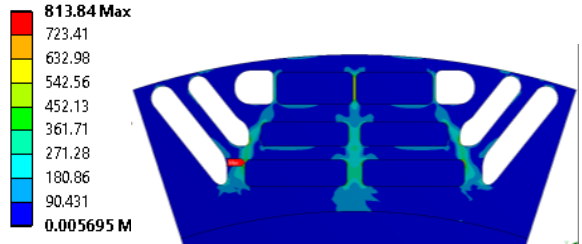

Second iteration
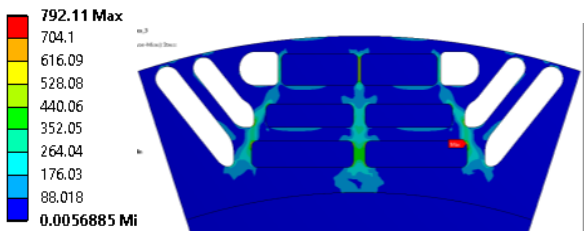

Third iteration
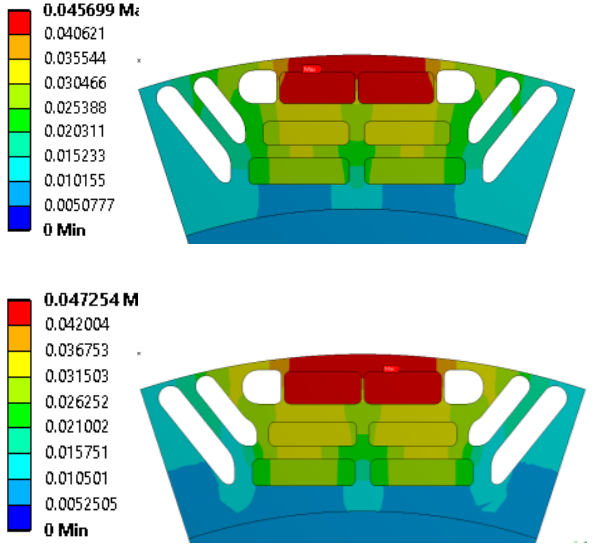

$0.048893 \mathrm{Ma}$
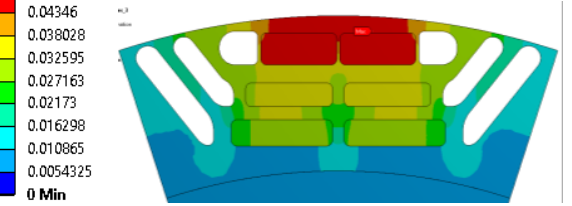


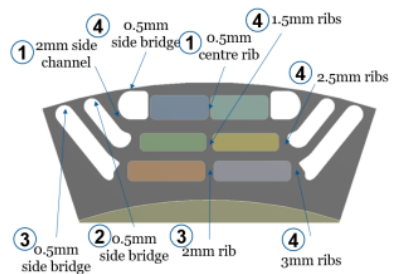

(a) Rotor layout and changes aplied

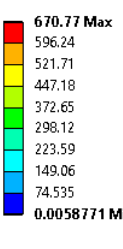

058771 Min

Fig. 11. Stress and deformation of the different iteration of D1 design with middle and side bridges.

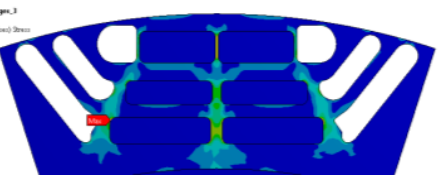

Forth iteration (final design D3)

(b) Stress

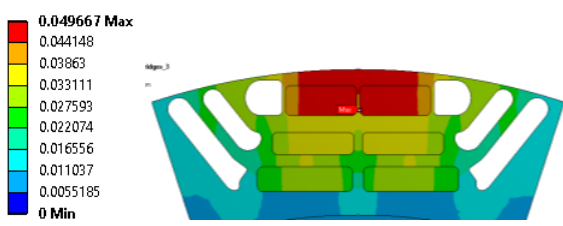

(c) Deformation
Table IV Temperatures of different machine parts.

\begin{tabular}{|l|c|c|}
\hline Machine part & $\begin{array}{c}\text { Temperature }\left({ }^{\circ} \mathbf{C}\right), \\
\text { Peak }\end{array}$ & $\begin{array}{c}\text { Temperature } \\
\left({ }^{\circ} \mathbf{C}\right), \text { Continuous }\end{array}$ \\
\hline Winding & 168.2 & 107.4 \\
\hline End-winding & 171.5 & 109.7 \\
\hline Rotor surface & 65.2 & 65.1 \\
\hline Rotor yoke & 65.3 & 65 \\
\hline Magnets & 65.2 & 65 \\
\hline Stator tooth & 75.9 & 68.2 \\
\hline Stator yoke & 75.3 & 68 \\
\hline
\end{tabular}

\section{COMPARSION WITH DIFFERENT PM TOPOLOGIES}

Other PM topologies have been explored to obtain the most suitable topology for the application requirements. Surface-mounted PM (SPM) machine with halbach magnetic orientation can meet the performance targets, however, the need for large quantity of rounded and diagonal magnets and thick retaining sleeve, as shown in Fig. 12 (a). Similarly, interior PM (IPM) machine requires large magnet quaintly to meet the target, Fig. 12 (b) presents the IPM topology. Therefore, PM-SynRel topology has been selected since this topology can meet the targets with the lowest PM material quantity. Table $\mathrm{V}$ compares the three topologies.

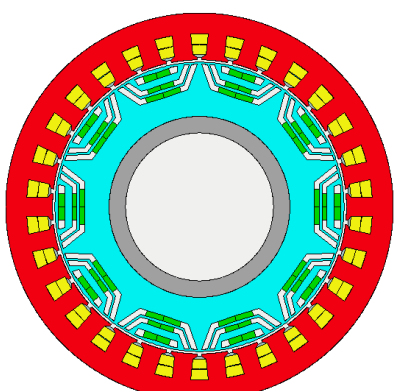

(a) PM-SynRel

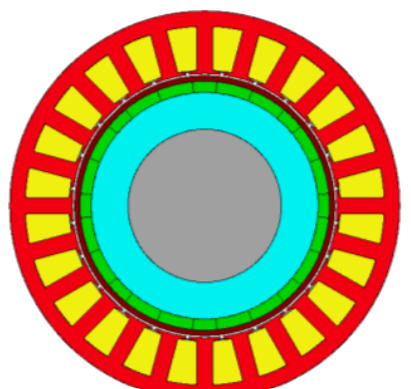

(b) SPM

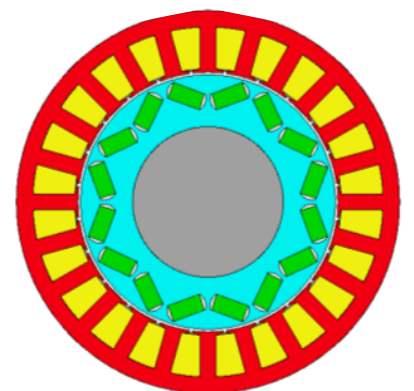

(c) IPM

Fig. 12 SPM and IPM machine topologies.

Table V Comparison of SPM, IPM and PM-SynRel.

\begin{tabular}{|l|c|c|c|}
\hline Parameter & PM-SynRel (a) & SPM (b) & IPM (c) \\
\hline PM Mass & 6.8 & 14.3 & 12.6 \\
\hline Mass & 122 & 136 & 117 \\
\hline Stack Length & 306 & 400 & 330 \\
\hline
\end{tabular}

\section{VIII.CONCLUSION}

This paper presents a multi-physics designing steps of a high torque density PM-SynRel electric motor designed for automotive application. The design procedure started with optimizing the design parameters using global multi-objective optimization. This step generated the first electromagnetically designed model D1 which achieved all the required targets. Following, mechanical investigation and designing of the rotor conducted to ensure mechanical safety. Mechanical bridges on the PM sides and middle have been employed, this design referred to by $\mathrm{D} 2$. This technique managed to reduces the mechanical stress from $2900 \mathrm{MPa}$ to the limit of $670 \mathrm{MPa}$. As a result, a reduction in the electromagnetic results have been observed due to the short circuit flux paths generated by the bridges. Thermal analysis have then been conducted to ensure the machine operates within the safe temperature limits. Finally, a comparison with SPM and IPM machines has been conducted to highlight the benefits of using PM-SynRel topology.

\section{REFERENCES}

[1] N. Bianchi, S. Bolognani, E. Carraro, M. Castiello and E. Fornasiero, "Electric Vehicle Traction Based on Synchronous Reluctance Motors," in IEEE Transactions on Industry Applications, vol. 52, no. 6, pp. 4762-4769, Nov.-Dec. 2016. 
[2] K. Grace, S. Galioto, K. Bodla and A. M. El-Refaie, "Design and Testing of a Carbon-Fiber-Wrapped Synchronous Reluctance Traction Motor," in IEEE Transactions on Industry Applications, vol. 54, no. 5, pp. 4207-4217, Sept.-Oct. 2018.

[3] P. B. Reddy, A. M. El-Refaie, S. Galioto and J. P. Alexander, "Design of Synchronous Reluctance Motor Utilizing Dual-Phase Material for Traction Applications," in IEEE Transactions on Industry Applications, vol. 53, no. 3, pp. 1948-1957, May-June 2017.
[4] M. D. Nardo, G. L. Calzo, M. Galea and C. Gerada, "Design Optimization of a High-Speed Synchronous Reluctance Machine," in IEEE Transactions on Industry Applications, vol. 54, no. 1, pp. 233243, Jan.-Feb. 2018.

[5] Z. Q. Zhu, W. Q. Chu and Y. Guan, "Quantitative comparison of electromagnetic performance of electrical machines for HEVs/EVs," in CES Transactions on Electrical Machines and Systems, vol. 1, no. 1, pp. 37-47, March 2017. 